\title{
Different reaction routes found in acid-catalyzed glycosylation of endo- and exo-glycals: competition between Ferrier rearrangement and protonation
}

\author{
Hui-Chang Lin, ${ }^{\mathrm{a}}$ Wen-Ping Du, ${ }^{\mathrm{a}}$ Chih-Chun Chang ${ }^{\mathrm{a}}$ and Chun-Hung Lin ${ }^{\mathrm{a}, \mathrm{b}, *}$ \\ ${ }^{a}$ Institute of Biological Chemistry, Academia Sinica, No. 128 Academia Road Section 2, Nan-Kang, Taipei 11529, Taiwan \\ ${ }^{\mathrm{b}}$ Institute of Biochemical Sciences, College of Life Science, National Taiwan University, Taipei 10617, Taiwan
}

Received 20 April 2005; revised 13 May 2005; accepted 16 May 2005

\begin{abstract}
Acid-mediated glycosylations of endo- and exo-glycals have been carried out in good to excellent yields, in which a mixture of two products is often obtained resulting from Ferrier rearrangement and protonation. The former reaction exclusively takes place with the $t$-butyl carbonate or hydroxyl substituent at the $\mathrm{C} 3$ position of endo-glycals, while the latter mainly occurs in the glycosylation of exo-glycals with allyl benzyl ether or acetate. In addition to the substituent effect, protecting groups are critical to determine the activity and favored reaction pathway. Furthermore, the method is applicable to $O$-, $C$-, and $N$-nucleophiles.

(c) 2005 Elsevier Ltd. All rights reserved.
\end{abstract}

Glycals are versatile building blocks in synthetic chemistry and have been extensively investigated for the synthesis of various important molecules, including tumor-associated antigens (such as Lewis y, globo $\mathrm{H}$, and $\mathrm{KH}-1$ ) and bioactive natural products (including ciclamycin, allosamidin, KS-502, and rebeccamycin). ${ }^{1}$ The glycosylation of endo-glycals can be carried out in a number of manners. For example, several Lewis acids were reported to catalyze Ferrier glycosylation ${ }^{2}$ to afford 2,3-unsaturated glycosides., ${ }^{3,4}$ Danishefsky's glycal assembly successfully utilized glycals as both glycosyl donors and acceptors in an iterative fashion ${ }^{5-8}$ so that the procedure can be operated in solid phase. ${ }^{9}$ NIS or NBS-mediated glycosylations were developed by Tatsuta et al. and Theim et al. for the synthesis of 2-deoxyglycosides. ${ }^{10,11}$ Although the same products can be prepared by the acid-catalyzed addition of alcohol nucleophiles to glycals, appearing to be a simpler and more direct way of glycosidation, so far only few studies were reported including the methods using triphenylphosphine hydrogenbromide, ${ }^{12}$ Dowex-50 resin $\left[\mathrm{H}^{+}\right]$ with the presence of $\mathrm{LiBr},{ }^{13}$ and TMSOTf-NEt ${ }_{3}{ }^{14}$ One major challenge in the preparation of 2-deoxyglyco-

\footnotetext{
Keywords: Glycosylation; Protonation; Rearrangement.

* Corresponding author. Tel.: +88622789 0110; fax: +88622651

4705; e-mail: chunhung@gate.sinica.edu.tw
}

sides originates from the tendency of the cyclic enol ether toward allylic rearrangement, which is usually observed to complicate many studies. Herein we report acid-catalyzed glycosyl additions of glycals, in which two products are generated in association with Ferrier rearrangement and protonation. With a suitable substituent introduced at the allylic position, the former reaction pathway can be exclusively formed in the glycosylation of endo-glycals whereas the latter is favored in that of exo-glycals. Major factors are examined to understand how they function to affect the reaction outcome.

Previously, we demonstrated that exo-glycals 1-4 are highly reactive as glycosyl donors in $\mathrm{BF}_{3} \cdot \mathrm{OEt}_{2}$-catalyzed reaction or under microwave radiation (Scheme 1). ${ }^{15}$ The reactions gave exclusively $\alpha$-glycosidation products that contain a vinyl group at the anomeric position, indicating the occurrence of allylic rearrangement. ${ }^{15}$ On the other hand, the trifluoroacetic acid (TFA)-catalyzed glycosylation exhibited a different scenario (Table 1) where a mixture of two structurally similar products was obtained. In addition to the minor product rising from the aforementioned Ferrier reaction, the major one contained the acetoxyethyl group at the anomeric center, as evidenced by the corresponding characteristic signals in ${ }^{1} \mathrm{H}$ and ${ }^{13} \mathrm{C}$ NMR spectra. ${ }^{16}$ The analysis based on the NOESY spectra indicated that the group 

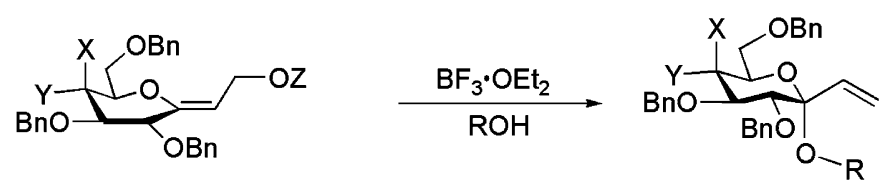

1, $X=O B n, Y=H, Z=A C$

2, $X=H, Y=O B n, Z=H$
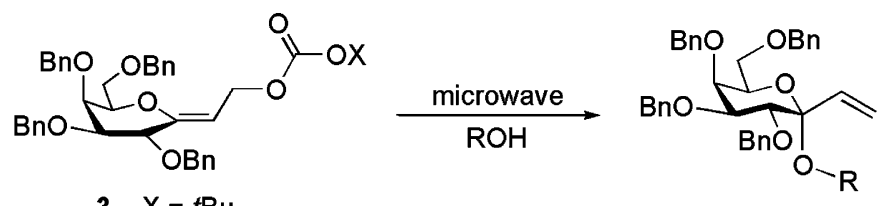

3, $X=t B u$

4, $\mathrm{X}=\mathrm{Ph}$

Scheme 1. exo-Glycals 1-4 are efficient glycosyl donors.

is located at $\beta$-position and thus the acceptor should approach from $\alpha$-position of the sugar ring during the glycosidation. ${ }^{17}$ In consistence with the previous reports, ${ }^{15}$ $\alpha$-stereoselectivity was always obtained in the reactions.

Table 1 demonstrates the glycosidations of exo-glycals 1, 3, and 5-9. The reactions were simple for operation to give products 10-29. With addition of TFA (10 equiv) to the mixture of exo-glycosyl donor and alcohol acceptor, the majority of reactions were complete in a short period of time (minutes to few hours) to give $77-95 \%$ yields. As shown by the 20 -fold difference of reaction time in entries $\mathrm{i}$ and $\mathrm{v}$, the $-\mathrm{CH}_{3}$ group of fucose made a significant contribution to enhance the reactivity, consistent with the report by Wong and co-workers. ${ }^{18}$ fucoType donors 5-9 varied extremely in reaction rates, clearly supporting a critical role played by the olefin substituent (e.g., the comparison between entries $\mathrm{v}$ and viii, the one between entries $x$ and xiii). The formation of both protonation and rearrangement products was observed in most of the reactions. As a consequence, the proposed oxonium ion develops during the glycosylation to proceed with two pathways of the rearrangement and protonation (Scheme 2). Apparently, the latter reaction is favored in the competition. It is interesting that a relatively higher percentage of the Ferrier reaction products were obtained in the reactions of exo-glycals 3 and $\mathbf{6}$ (entries iv, vi, and xi).

Alternatively, the reactions of endo-glycals 30-33 represent an intriguing distinction from the prior result. As shown in Table 2, the glycosylation reactions of various 4,6-di- $O$-benzyl-D-galactals were carried out in TFAcontaining $\mathrm{CH}_{2} \mathrm{Cl}_{2}$ to generate glycosides 34 41. Alcohol acceptors (2-3 equiv) were used in the reactions. The substituents of $t$-butyl carbonate (30) and hydroxyl group (31) at $\mathrm{C} 3$ position led to the formation of 2,3unsaturated glycosides exclusively (entries $\mathrm{i}-\mathrm{-vi}$ ), which echoed to the studies of exo-glycals $\mathbf{3}$ and $\mathbf{6}$ (see Table 1 , entries iv, vi, and xi), suggesting the possibility to develop a positive (or partial positive) charge at $\mathrm{C} 3$ to trigger the Ferrier reaction. The relatively more constrained conformation of endo-glycals (with two $\mathrm{sp}^{2}$ carbons in the sugar ring), in comparison with that of exo-glycals (with one $\mathrm{sp}^{2}$ carbon), also favors the rearrangement to occur. As a result, proper combination of substituent and conformation likely contributes to the exclusive occurrence of the Ferrier rearrangement in entries i-vi. Other issues, however, may be part of the cause here and cannot be simply ruled out.

On the other hand, the replacement of $\mathrm{C} 3$ functionality with acetate (32) or benzyl ether (33) resulted in the formation of both protonation and rearrangement products (entries vii-ix). Surprisingly, the production of 2deoxygalactosides is relatively favored. The contrasting result to those of $\mathbf{3 0}$ and $\mathbf{3 1}$ provides additional evidence that the functional group at the allylic position cannot only fine-tune the reactivity, but also dominate, which reaction pathway is preferred. Recently, Vankar et al. reported that 3,4,6-tri- $O$-acetyl-D-glucal was used in the $\mathrm{HClO}_{4}-\mathrm{SiO}_{2}$-mediated synthesis of 2,3-unsaturated glycosides. ${ }^{19}$ Applying our TFA method for the glycosylation of 3,4,6-tri- $O$-acetyl-D-galactal (33a) also led to occurrence of the Ferrier reaction only. The results of peracetylated glycosyl donors were different from those of the analogous substrates $\mathbf{3 2}$ and $\mathbf{3 3}$ (entries vii-ix), revealing that protecting groups may serve as another essential factor. In general, the protecting groups of glycosyl donors are a determinant on the glycosylation rate, ${ }^{18,20}$ depending on if they stabilize or destabilize the putative cationic transition state. We propose that electron-donating groups (e.g., benzyl ethers) facilitate the protonation pathway, which is possibly due to the $\pi^{*}$-stabilization by the interaction either from direct $\sigma(\mathrm{C}-\mathrm{O})$ or from oxygen lone pair electron through space, especially when electron donating protective group is introduced. On the contrary, the existence of electron-withdrawing groups (e.g., acetates) makes the oxonium ion relatively less stable so that allylic rearrangement has the advantage to form a more stable $\alpha, \beta$-conjugated oxonium ion (similar to the top transition state in Scheme 2). The results of Tables 1 and 2 are thus contributed by the effects of the allylic substituent and protecting group, which may need more supporting evidence for further corroboration.

Substitution of TFA with various acids was also carried out. Like the synthesis of 2-deoxyglycosides by a catalytic amount of triphenylphosphine hydrogenbromide 
Table 1. Glycosylations of exo-glycals $1,3,5-9$ with various alcohols ${ }^{\mathrm{a}}$
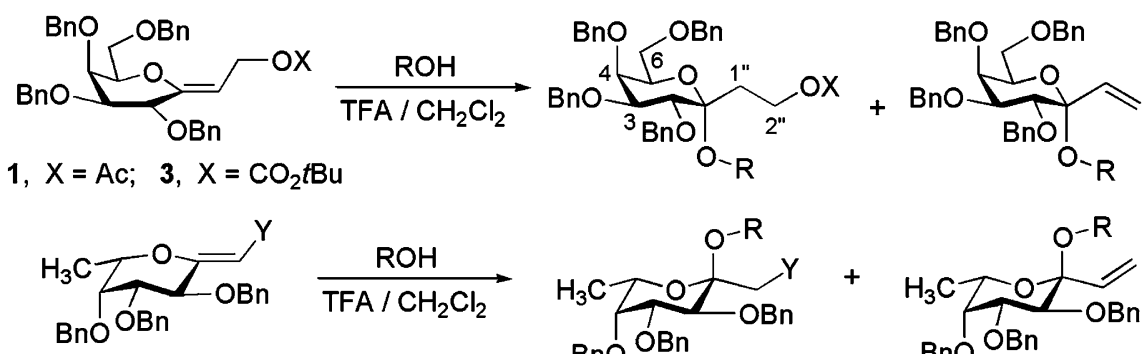

5, $\mathrm{Y}=\mathrm{CH}_{2} \mathrm{OAc} ; 6, \mathrm{Y}=\mathrm{CH}_{2} \mathrm{OH}$;

7, $\mathrm{Y}=\mathrm{CH}_{2} \mathrm{OBn} ; 8, \mathrm{Y}=\mathrm{COOEt} ; 9, \mathrm{Y}=\mathrm{CH}_{2} \mathrm{CH}_{2} \mathrm{CH}_{3}$

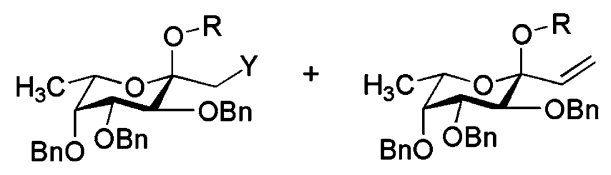

\begin{tabular}{|c|c|c|c|c|c|}
\hline Entry & Donor & Acceptor (ROH) & Time (min) & \multicolumn{2}{|c|}{$\begin{array}{c}\text { Protonation + rearrangement } \\
\text { products (yield) }\end{array}$} \\
\hline i & 1 & & 60 & $\mathbf{1 0}(85 \%)$ & $11(10 \%)$ \\
\hline ii & 1 & Oे & 90 & $12(75 \%)$ & $13(10 \%)$ \\
\hline iii & 1 & no & 120 & $14(70 \%)$ & $15(7 \%)$ \\
\hline iv & 3 & & 90 & $16(66 \%)$ & $17(22 \%)$ \\
\hline $\mathrm{v}$ & 5 & & 3 & $18(71 \%)$ & $19(12 \%)$ \\
\hline vi & 6 & & 15 & $20(46 \%)$ & $19(38 \%)$ \\
\hline vii & 7 & $\mathrm{H}$ & 40 & $21(76 \%)$ & $19(8 \%)$ \\
\hline viii & 8 & & 1440 & $22(78 \%)$ & $-(0 \%)$ \\
\hline ix & 9 & $\mathrm{OH}$ & 2 & $23(94 \%)$ & $-(0 \%)$ \\
\hline $\mathrm{x}$ & 5 & $-\mathrm{OH}$ & 30 & $24(85 \%)$ & $25(9 \%)$ \\
\hline xi & 6 & $\mathrm{H}$ & 40 & $26(50 \%)$ & $25(29 \%)$ \\
\hline xii & 7 & $\succ \mathrm{OH}$ & 70 & $27(72 \%)$ & $25(10 \%)$ \\
\hline xiii & 8 & $\searrow-\mathrm{OH}$ & 2880 & $28(70 \%)^{b}$ & $-(0 \%)$ \\
\hline xiv & 9 & $>\mathrm{OH}$ & 80 & $29(77 \%)$ & $-(0 \%)$ \\
\hline
\end{tabular}

${ }^{a}$ All reactions were carried out at $0-25^{\circ} \mathrm{C}$ in $\mathrm{CH}_{2} \mathrm{Cl}_{2}$ with alcohol nucleophiles in the presence of TFA (10 equiv) and molecular sieves (4 $\AA$ ).

${ }^{\mathrm{b}}$ Twenty percentage of the starting material was recovered.

(TPHB), ${ }^{12}$ the reaction of exo-glycal 1 with 1-butanol gave only the protonation product (10). The TPHBmediated glycosylation only allowed the protonation pathway to take place in preference to the Ferrier rearrangement, which was well interpreted based on softhard principle, that is, the protonation occurring at the softer $\beta$-enolic carbon instead of the harder allylic oxygen. ${ }^{12}$ It will be intriguing to examine if the TPHB method (or the preferential protonation at the $\beta$-enolic carbon) is subjected to the effects of substituent and pro- tecting group. Meanwhile, the studies with other acids turned out to be less desirable owing to lower yield or/ and lower selectivity in our hands. Scheme 3 shows two examples to utilize methanesulfonic acid, which are analogous to the first two entries of Table 1. Additionally, the acid catalyzed-glycosylation was found useful for the use of $C$ - and $N$-nucleophiles. Table 3 presents that endo- and exo-glycals react with allyl-, propargyl-, and azido-trimethylsilane to obtain glycosides 42-48. Interestingly, except for entry vii, the 


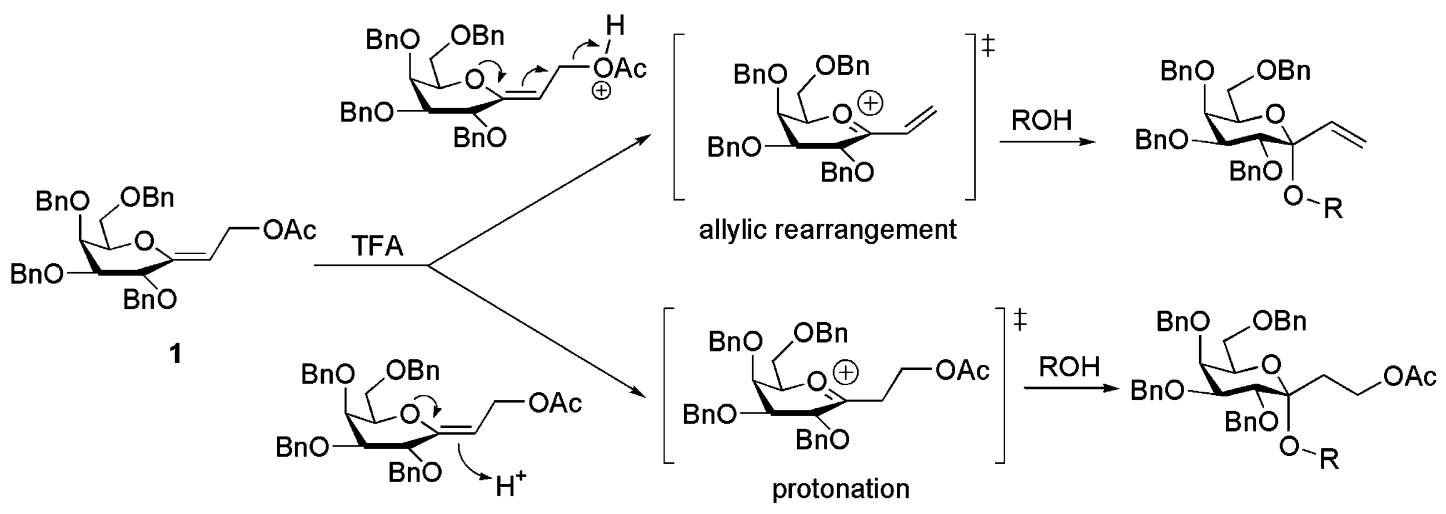

Scheme 2. Two possible pathways proposed to explain the formation of both rearranged and protonated products.

Table 2. Glycosylations of endo-glycals $\mathbf{3 0}-\mathbf{3 3}$ with various alcohols ${ }^{\mathrm{a}}$

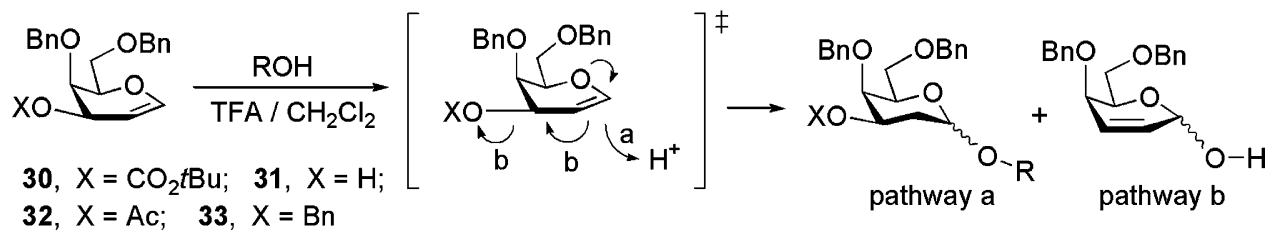

33a, 3,4,6-tri-O-acetyl-D-galactal

\begin{tabular}{|c|c|c|c|c|c|}
\hline Entry & Donor & Acceptor (ROH) & Time (min) & \multicolumn{2}{|c|}{$\begin{array}{l}\text { Protonation }+ \text { rearrangement } \\
\text { products (yield) }\end{array}$} \\
\hline $\mathrm{i}$ & 30 & & 60 & $-(0 \%)$ & $34(85 \%)^{b}$ \\
\hline ii & 30 & & 120 & $-(0 \%)$ & $35(83 \%)^{\mathrm{b}}$ \\
\hline iii & 30 & & 120 & $-(0 \%)$ & $36(75 \%)^{b}$ \\
\hline iv & 31 & & 30 & $-(0 \%)$ & $37(86 \%)^{\mathrm{b}}$ \\
\hline $\mathrm{v}$ & 31 & & 30 & $-(0 \%)$ & $35(78 \%)^{b}$ \\
\hline vi & 31 & & 30 & $-(0 \%)$ & $38(75 \%)^{b}$ \\
\hline vii & 32 & & 60 & $39(64 \%)$ & $35(24 \%)$ \\
\hline viii & 32 & & 30 & $40(51 \%)$ & $38(30 \%)$ \\
\hline ix & 33 & & 150 & $41(61 \%)$ & $37(24 \%)$ \\
\hline $\mathrm{x}$ & $33 \mathbf{a}$ & & 150 & $-(0 \%)$ & $37 \mathbf{a}(82 \%)^{\mathrm{c}}$ \\
\hline
\end{tabular}

${ }^{a}$ All reactions were carried out at $0-25^{\circ} \mathrm{C}$ in $\mathrm{CH}_{2} \mathrm{Cl}_{2}$ with alcohol nucleophiles in the presence of TFA (10 equiv) and molecular sieves (4 $\mathrm{A}$ ).

${ }^{\mathrm{b}}$ The $\alpha$-anomer is predominant with $\alpha / \beta$ ratio of $8 / 1-15 / 1$ on the basis of ${ }^{1} \mathrm{H}$ NMR integration.

${ }^{\mathrm{c}}$ Product $\mathbf{3 7} \mathbf{a}$ is the same as $\mathbf{3 7}$ except for the acetate protecting group. 

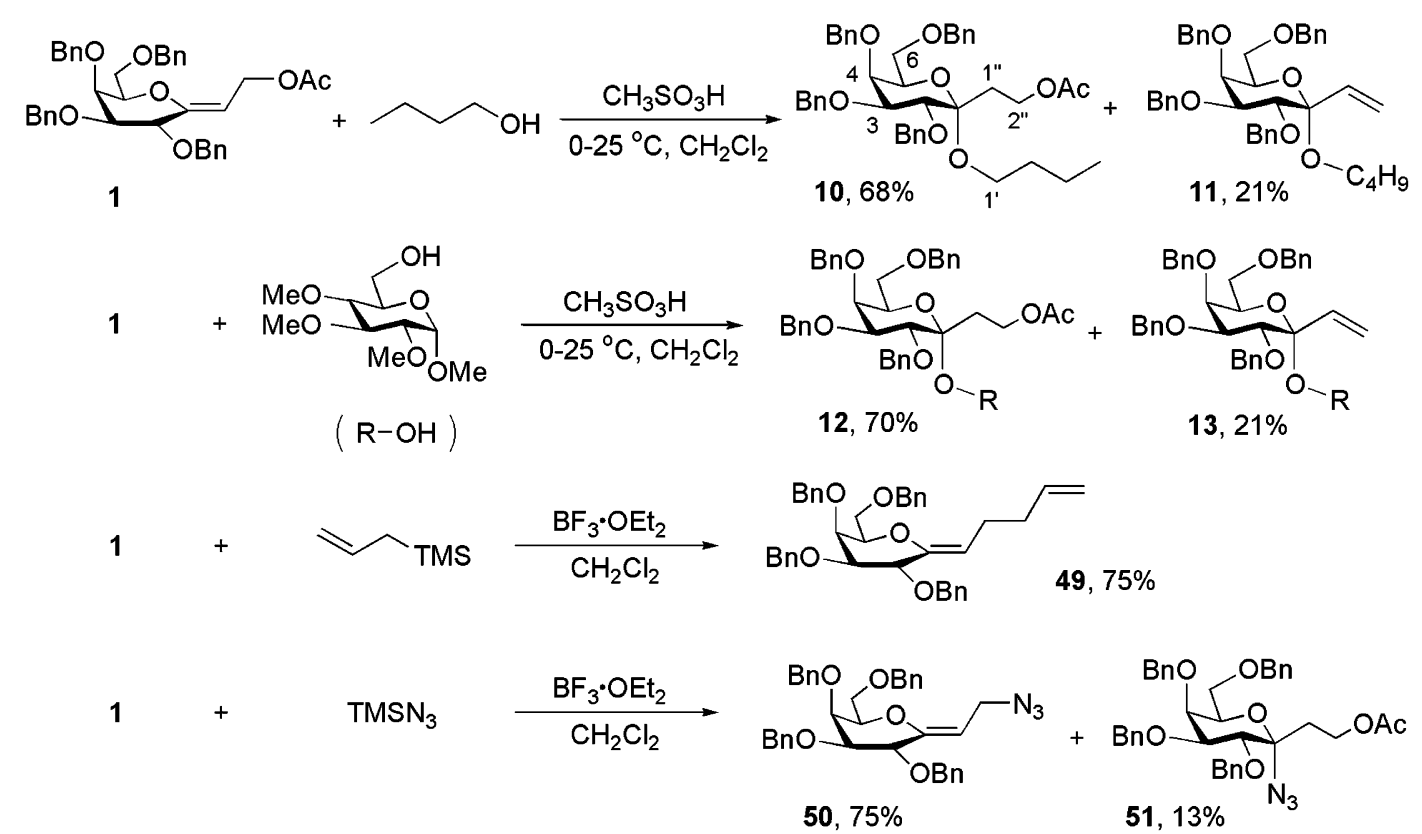

Scheme 3. Glycosylation reactions catalyzed by methanesulfonic acid or boron trifluoride etherate.

Table 3. Reactions of glycals with $C$ - and $N$-nucleophiles ${ }^{\mathrm{a}}$

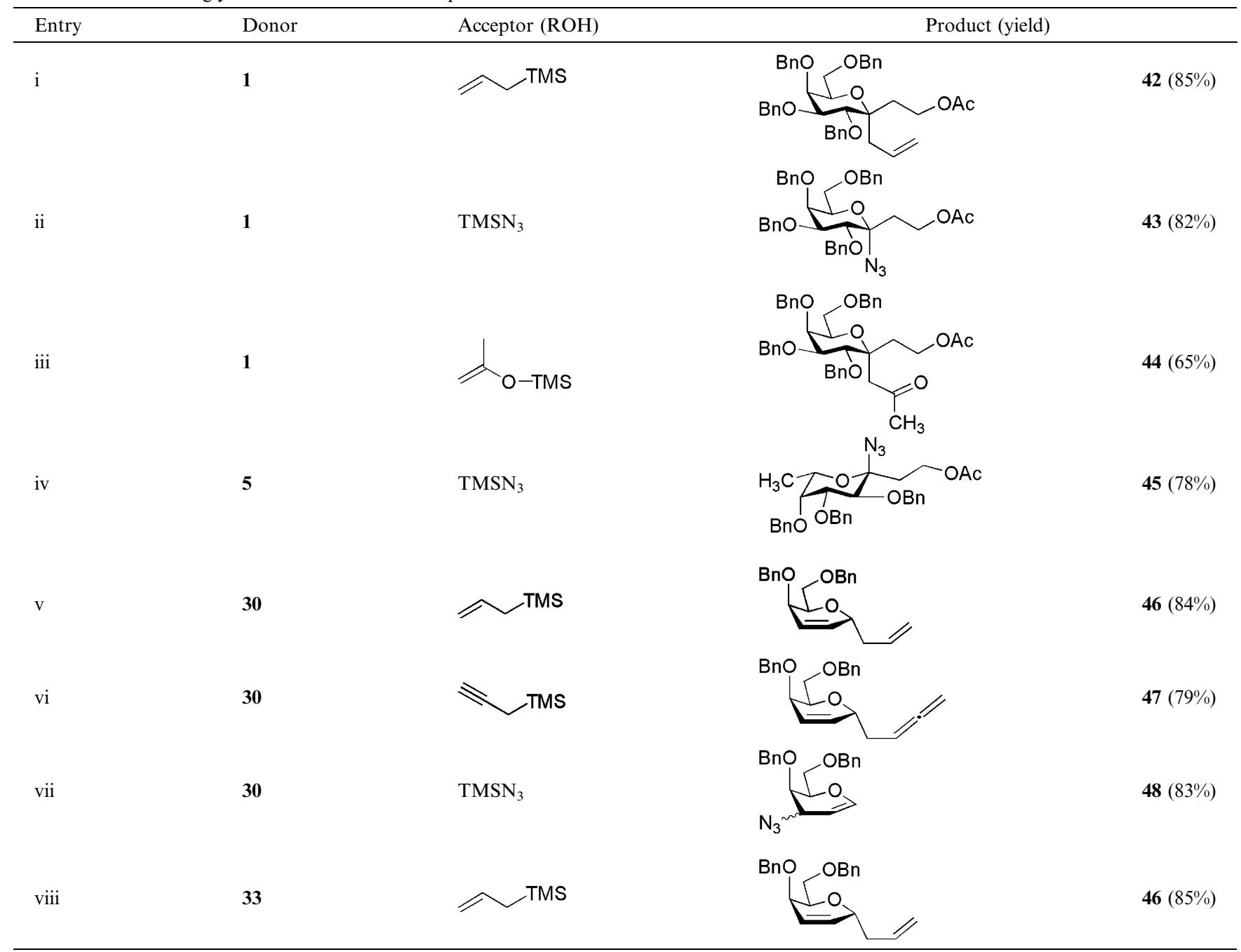

\footnotetext{
${ }^{\text {a }}$ All reactions were carried out at $0-25^{\circ} \mathrm{C}$ in $\mathrm{CH}_{2} \mathrm{Cl}_{2}$ with nucleophiles in the presence of TFA (10 equiv) and molecular sieves (4 $\mathrm{A}$ ).
} 
selectivity was greatly enhanced here in comparison with the glycosylation of $O$-nucleophiles, including the $\alpha$ stereoselectivity and selective product formation from a preferential pathway. Nevertheless, the parallel reactions using other Lewis acids often afforded undesired product(s). For example, a diene product 49 was obtained owing to the direct substitution of exo-glycal 1 with allyl trimethylsilane in the presence of $\mathrm{BF}_{3} \cdot \mathrm{OEt}_{2}$. The same condition with $\mathrm{TMSN}_{3}$ gave azide adduct $\mathbf{5 0}$ as the major product $(75 \%)$.

In conclusion, we have conducted in detail the investigation of acid-catalyzed glycosylation of endo- and exoglycals that are simple and can be finished efficiently in good to excellent yields. The reactions can be applied for the glycosyl additions of $\mathrm{O}-, \mathrm{C}$-, and $\mathrm{N}$-nucleophiles. The carbonate or hydroxyl group at $\mathrm{C} 3$ position exclusively adopted the Ferrier reaction pathway in the reactions of endo-glycals, while the acetate and benzyl ether substituents predominantly gave a protonation product in those of exo-glycals. Particularly the former reactions are useful for the synthesis of 2,3-unsaturated- $\alpha$-glycosides. In addition to providing an expeditious glycosylation procedure, our work represents the first report to clearly display the different reactivity between endoand exo-glycals, and demonstrate both reaction pathways to be in the control of the allyl substituent and protecting group. Current efforts are in progress to study if other factors play a role in the competition and will be published in due course.

\section{Acknowledgements}

The authors thank the financial support from the National Science Council of Taiwan (NSC93-2113M-001-003 and NSC93-2113-M-001-034) and Academia Sinica, Taiwan.

\section{Supplementary data}

${ }^{1} \mathrm{H}$ and ${ }^{13} \mathrm{C}$ NMR spectra of 45 compounds are available (75 pages). Supplementary data associated with this article can be found, in the online version, at doi:10.1016/ j.tetlet.2005.05.061.

\section{References and notes}

1. Williams, L. J.; Garbaccio, R. M.; Danishefsky, S. J. In Carbohydrates in Chemistry and Biology; Ernst, B., Hart, G. W., Sinay, P., Eds.; Wiley-VCH Verlag GmbH: Weinheim, Germany, 2000; Vol. 1, pp 61-92.
2. (a) Ferrier, R. J. J. Chem. Soc. 1964, 5443; (b) Ciment, D. M.; Ferrier, R. J. J. Chem. Soc. C 1966, 441.

3. (a) Takhi, M.; Abdel-Rahman, A. A.-H.; Schmidt, R. R. Synlett 2001, 427; (b) Yadav, J. S.; Reddy, B. V. S.; Murphy, C. V. S. R.; Kumar, G. M. Synlett 2000, 1451.

4. (a) Das, S. K.; Reddy, K. A.; Roy, J. Synlett 2003, 1607 1610; (b) Swamy, N. R.; Venkateswarlu, Y. Synthesis 2002, 598 .

5. (a) Seeberger, P. H.; Danishefsky, S. J. Acc. Chem. Res. 1998, 31, 685; (b) Seeberger, P. H.; Danishefsky, S. J. Angew. Chem., Int. Ed. 1997, 36, 491; (c) Danishefsky, S. J.; Bilodeau, M. T. Angew. Chem., Int. Ed. 1996, 35, 1318.

6. (a) Zheng, C.; Seeberger, P. H.; Danishefsky, S. J. Angew. Chem., Int. Ed. 1998, 37, 786; (b) Goering, B. K. Ph.D. Dissertation, Cornell University, 1995.

7. Zheng, C.; Seeberger, P. H.; Danishefsky, S. J. J. Org. Chem. 1998, 63, 1126.

8. (a) Seeberger, P. H.; Eckhardt, M.; Gutteridge, C. E.; Danishefsky, S. J. J. Am. Chem. Soc. 1997, 119, 10064; (b) Danishefsky, S.; Kato, N.; Askin, D.; Kerwin, J. F., Jr. J. Am. Chem. Soc. 1982, 104, 360.

9. Roberge, J. Y.; Beebe, X.; Danishefsky, S. J. Science 1995, 269, 202.

10. Tatsuta, K.; Fujimoto, K.; Kinoshita, M.; Umezawa, S. Carbohydr. Res. 1977, 54, 85.

11. Thiem, J.; Karl, H.; Schwentner, J. Synthesis 1978, 696.

12. Bolitt, V.; Mioskowski, C.; Lee, S.-G.; Falck, J. R. J. Org. Chem. 1990, 55, 5812.

13. Sabesan, S.; Neira, S. J. Org. Chem. 1991, 56, 5468.

14. (a) Kolar, C.; Kneissl, G. Angew. Chem. Int. Ed. Engl. 1990, 29, 809; (b) Kaila, N.; Blumenstein, M.; Bielawska, H.; Franck, R. W. J. Org. Chem. 1992, 57, 4576.

15. (a) Lin, H.-C.; Yang, W.-B.; Gu, Y.-F.; Chen, C.-Y.; Wu, C.-Y.; Lin, C.-H. Org. Lett. 2003, 5, 1087-1089; (b) Lin, H.-C.; Chang, C.-C.; Chen, J.-Y.; Lin, C.-H. Tetrahedron: Asymmetry 2005, 16, 297; (c) Chang, C.-F.; Yang, W.-B.; Chang, C.-C.; Lin, C.-H. Tetrahedron Lett. 2002, 43, 6515.

16. For example, the ${ }^{1} \mathrm{H}$ NMR spectra of the glycosylation product 10 indicated the $\mathrm{H}-1^{\prime \prime}$ resonance appeared at $\delta$ $2.08(t, J=7.3 \mathrm{~Hz}, 2 \mathrm{H}), \mathrm{H}-2^{\prime \prime}$ at $\delta 3.90(\mathrm{~m}, 1 \mathrm{H})$ and 4.12 $(\mathrm{m}, 1 \mathrm{H})$, and $\mathrm{CH}_{3} \mathrm{CO}-$ at $\delta 1.90(\mathrm{~s}, 3 \mathrm{H})$. The signals at $\delta$ 20.89 and 170.8 corresponding to the $\mathrm{CH}_{3} \mathrm{CO}-$ and $\mathrm{CH}_{3} \mathrm{CO}$ - resonances, respectively, were found in the ${ }^{13} \mathrm{C}$ NMR spectra of the same molecule. Please see the numbering structure in Scheme 3.

17. The NOESY spectra of 10, for instance, exhibited the cross-peaks between $\mathrm{H} 2(\delta 3.97)$ and $\mathrm{H}^{\prime \prime}(\delta 2.08)$, as well as $\mathrm{H} 5(\delta 3.80)$ and $\mathrm{H}^{\prime}(\delta 3.43)$.

18. Zhang, Z.; Ollmann, I. R.; Ye, X.-S.; Wischnat, R.; Baasov, T.; Wong, C.-H. J. Am. Chem. Soc. 1999, 121, 734.

19. Agarwal, A.; Rani, S.; Vankar, Y. D. J. Org. Chem. 2004, $69,6137$.

20. The effect has been long recognized. Please see (a) Paulson, H.; Richter, A.; Sinnwell, H.; Stenzel, W. Carbohydr. Res. 1974, 38, 312; (b) Fraser-Raid, B.; Bocter, B. Can. J. Chem. 1969, 47, 393; (c) Feather, M. S.; Harris, J. F. J. Org. Chem. 1965, 30, 153. 